\title{
Indirect facilitation drives species composition and stability in drylands
}

\author{
Alain Danet · Florian Dirk Schneider · Fabien \\ Anthelme · Sonia Kéfi
}

6 Received: date / Accepted: date

\begin{abstract}
Dryland ecosystems are likely to respond discontinuously to gradual changes in environmental conditions. Direct facilitation between plants, whereby plants improve the local environmental conditions for others, has been shown to be a mechanism contributing to these discontinuous ecosystem transitions. Theoretical models describing dryland vegetation dynamics often consider a single plant species and one type of facilitation, namely direct facilitation. However, another type of facilitation indirect facilitation - is widespread in dryland ecosystems as well ; it is performed by plants protected against grazing, the nurses, when this protection extends to other plants growing in their neighborhood that are deprived of such protection, the protegees. Little is known about the long term effects of indirect facilitation on dryland dynamics. Here, we developed and analyzed a theoretical model including two species - a nurse and a protegee - and indirect facilitation through grazing. We investigated the effects of indirect facilitation on species composition, species spatial clustering and the stability of dryland ecosystems. We showed that indirect facilitation through grazing enables the stable coexistence of the nurse and the protegee and allows the reversibility of the protegee extinction. Surprisingly, the strength of indirect facilitation affected neither the total nor the inter-specific vegetation clustering. Our study highlights that spatially explicit grazing protection may affect species
\end{abstract}

Alain Danet, Florian Dirk Schneider, Sonia Kéf

ISEM, CNRS, Univ. Montpellier, IRD, EPHE, Montpellier, France

Alain Danet, Fabien Anthelme

AMAP, CIRAD, IRD, CNRS, INRA, Université de Montpellier, Montpellier, France

Alain Danet

Centre d'Ecologie et des Sciences de la Conservation, UMR 7204 MNHN-CNRS-Sorbonne Université, Muséum national d'Histoire naturelle de Paris, 43 rue Buffon, 75005, Paris, France

Florian Dirk Schneider

ISOE - Institute for Social-Ecological Research, Biodiversity and People, Frankfurt am Main, Germany; Senckenberg Biodiversity and Climate Research Center BiK-F, Ecosystem Services and Climate, Frankfurt am Main, Germany

E-mail:

alain.danet@mnhn.fr, florian.dirk.schneider@gmail.com, fabien.anthelme@ird.fr, sonia.kefi@umontpellier.fr 
composition, the stability of dryland ecosystems and gives hints about how species interactions translate into spatial clustering.

Keywords grazing $\cdot$ indirect facilitation $\cdot$ stability $\cdot$ drylands $\cdot$ alternative stable states $\cdot$ catastrophic shifts $\cdot$ resilience

\section{Introduction}

It has long been recognized in the ecological literature that facilitation has been relatively understudied compared to other types of ecological interactions, such as competition and predation (e.g. Stachowicz, 2001; Bruno et al. 2003; Bulleri et al., 2016), and especially so theoretically. Facilitation has nonetheless been reported as a central mechanism in the organisation of plant communities across many ecosystem types, such as salt marches, intertidal (Bertness and Callaway, 1994), alpine (Cavieres et al. 2014), tropical alpine (Anthelme and Dangles, 2012), Mediterreanean and dryland ecosystems (Lortie and Callaway, 2006). The term 'facilitation' refers to a positive effect of one organism, often called a 'nurse', on another organism, often called a 'protegee' (Callaway, 2007). In plant communities, the nurse is often an adult and the protegee a sapling, which is a critical stage for plant recruitment.

Facilitation can be categorized as 'direct' or 'indirect'. Direct facilitation has been more frequently studied and occurs when a nurse improves the recruitment success of the protegee below or close to its canopy by improving the local environmental conditions, e.g. by decreasing soil erosion, evapotranspiration, and temperature amplitudes (Callaway, 2007, Filazzola and Lortie, 2014). Indirect facilitation requires that a third organism be involved in the interaction. This occurs for example in competitive networks, when the direct negative effect of one species on a second species reduces the competitive effect of that second species on a third one (Aschehoug et al. 2016, Levine et al., 2017). There has been a growing research interest for such indirect facilitative effects, which are common but still understudied in plant communities (Atsatt and O'Dowd, 1976, Olff et al., 1999, Bisigato et al., 2005, Smit et al., 2006. Callaway, 2007, Graff et al. 2007; Anthelme and Michalet, 2009, Graff and Aguiar, 2011; Lortie et al., 2016, Danet et al. 2018). Particularly in drylands and open shrublands with large herbivores, indirect facilitation is frequently observed through associational grazing resistance: if an unpalatable nurse is present in the landscape, a palatable protegee sapling growing close to it will be less likely to be consumed (Graff et al., 2007; Smit et al., 2006). The nurses, by decreasing the feeding rate of the grazers on neighbourhing protegees, have an indirect positive effect on the protegees.

By impacting local-scale plant performance under stress and disturbance, direct and indirect facilitation affect community structure and ecosystem functioning. For instance, the presence of direct or indirect facilitation in plant communities supports a wider variety of species traits, thus promoting functional diversity, i.e. the coexistence of different species strategies (Schöb et al., 2012, 2017; Danet et al., 2017, 2018). Direct facilitation has also been shown to increase species richness (Cavieres et al. 2014) and phylogenetic diversity (Valiente-Banuet and Verdú. 2007) because 
it allows the recruitment of species that are not adapted to local environmental conditions. It can increase productivity by improving resource use efficiency in stream mesocosms (Cardinale et al. 2002) or by concentrating scarce resources in space, such as water and organic nutrients in drylands (Rietkerk et al., 2002, Kéfi et al. 2007b 2010). Moreover, direct facilitation has been suggested to be a mechanism which can contribute to the emergence of catastrophic shifts, meaning abrupt ecosystem responses to gradual changes in environmental conditions (see Kéfi et al. 2016 for a review).

In drylands, direct facilitation has been well studied and has been shown to have remarkable ecosystem-wide consequences. Notably, it is a key mechanisms in the emergence of the characteristic spatial organization of the vegetation observed in most drylands (Rietkerk et al., 2004, Rietkerk and van de Koppel, 2008, Kéfi et al. 2007b a 2011). Indeed, the presence of plants improves the local environmental conditions, e.g. by increasing the infiltration rate of water in the soil, decreasing soil erosion and creating shading below and close to the plants' canopy (Rietkerk et al. 2000). This increases plant recruitment under the canopy of an adult plant compared to the surrounding bare soil, leading to spatial aggregation of plants and the formation of vegetation patches. By improving conditions that favor plants, direct facilitation contributes to generating a positive feedback loop, i.e. more vegetation leads to better local environmental conditions, which leads to more plants in the landscape. Such a positive feedback can generate bistability and catastrophic shifts at the ecosystem scale once a threshold, or 'tipping point', in environmental conditions or external pressure is passed (Kéfi et al., 2007b, Rietkerk et al. 2004). Overall, the spatial heterogeneity in environmental conditions, and thereby in the recruitment probability of new individuals, created by direct facilitation determines for a large part the spatial structure of the vegetation (Couteron et al. 2014) and plays a key role in the stability of the ecosystem.

In a similar way as direct facilitation, indirect facilitation through grazing also creates spatial heterogeneity in the environmental conditions perceived by plants (see e.g. Olff et al. 1999, for a review). Unpalatable nurse plants indeed create pockets of habitat for the protegees that are less accessible to grazers, thereby reducing the probability for a given protegee to be eaten by a grazer compared to areas farther away from the nurse. Therefore, nurse plants induce spatial heterogeneity in the protegees' mortality due to grazing. While most of the studies mentioned above have focused on the effect of direct facilitation among plants in general, there is much less research on indirect facilitation, and in particular on the mechanism of associational resistance to grazing and its effects at the ecosystem level. Therefore, how indirect facilitation affects dryland ecosystems, their spatial organization and stability, remains largely an open question.

Schneider and Kéfi (2016) studied the effects of intraspecific indirect facilitation through grazing in a model of dryland ecosystems (Kéfi et al. 2007b, 2011). They showed that indirect facilitation leads to more sudden and unexpected catastrophic ecosystem shifts to desertification than in the case of spatially homogeneous grazing pressure. A drawback of these previous modelling approaches is that they have typically modelled one vegetation compartment, thereby ignoring the diversity of species characteristics (Soliveres et al., 2012). 
Indirect facilitation through grazing also raises the question of the mechanisms of coexistence between the nurse and the protegee, two species in competition. Many nurse/protegee species pairs co-occur in nature (Atsatt and O'Dowd, 1976, Olff et al. 1999; Callaway, 2007), but the mechanisms leading to such a coexistence are not known. Previous studies have shown that spatial environmental heterogeneity may enable coexistence between competing species (Chesson, 2000a b; Muko and Iwasa 2000). Furthermore, palatability differences between competing species may create conditions for stable coexistence (Pacala and Crawley, 1992; Chesson, 2000b). Whether the spatial heterogeneity in plant mortality created by indirect facilitation through grazing can promote coexistence between the nurse and the protegee at the landscape scale is still an open question. Additionally Schöb et al. (2014) and García et al. (2016) found that facilitation comes at a cost for the nurse. We however do not know how the individual cost of the nurse for facilitating the protegee is translated at the landscape scale.

Overall, current theoretical studies on catastrophic shifts and facilitation in drylands have neglected the diversity of species and of their characteristics. While empirical studies have focused on individual performance and local community structure, they have rarely addressed the effects of direct and indirect facilitation at the landscape scale (but see Kikvidze et al., 2015). This study aims to provide new insights into the effects of indirect facilitation through grazing at the landscape scale and on long-term dynamics, thus contributing to bridge the gap between catastrophic shift theory in drylands and community ecology. We ask if indirect facilitation, as a local interaction, can create stable coexistence between two species in competition at the landscape scale, by extending the niche of the protegee. We expect that (1) indirect facilitation promotes the coexistence between the two species in competition. Since stable coexistence means that the nurse plant is supporting a competitor in the landscape, we investigate if indirect facilitation through grazing comes at a cost for the nurse population. We expect that (2) indirect facilitation through grazing may lead to the exclusion of the nurse due to the cost of maintaining a competitor. By modifying the dynamics of the protegee species, we expect that (3) indirect facilitation through grazing modifies the regime shift of the protegee along aridity and grazing gradients. Finally, since indirect facilitation through grazing increases the recruitment of protegees close to the nurse, we expect that (4) the strength of indirect facilitation through grazing increases the spatial clustering between nurses and protegees.

\section{Methods}

\subsection{Model}

In the present study, modelled the dynamics of two plant species in a dryland ecosystem. The model includes two species, a nurse and a protegee, respectively a palatable and an unpalatable species. The key mechanism we are interested in is indirect facilitation through grazing, which is an interspecific interaction from the unpalatable species, also called the 'nurse', to the palatable species, also referred to as the 'protegee'. In addition, our model assumes that both species perform direct facilitation on 
the local environment, meaning that they both increase the local environmental conditions and thereby the recruitment of seedlings in their neighborhood. We believe that the model presented in this study is generic enough to provide insights into the effect of indirect facilitation through grazing on the dynamics of dryland ecosystems.

General description We modelled the spatio-temporal dynamics of two plant species in a dryland landscape, a nurse and a protegee, using a stochastic cellular automaton model (CA). Such models have proven their ability to reproduce realistic spatial vegetation patterns (Kéfi et al. 2007a, 2011). A dryland ecosystem is represented as a two dimensional grid of cells. Each cell of the grid can at any given time be in one of four possible states: occupied by a plant, which can be a nurse $(N)$ or a protegee $(P)$, empty $(0)$ or degraded (-). Each cell is thought to be the size of about $1 \mathrm{~m}^{2}$, i.e. the space occupied by an average adult shrub. At each time step (time is discrete), the status of each cell of the grid can change from one of the possible states to another of the possible states at a rate that determines the probability per unit time of the different events (cf dynamical rules described hereafter) (Kéfi et al., 2007b, van Baalen, $2000)$. The transition rate of a cell from one state to another $\left(w_{\{i, j\}}\right)$ can depend on the neighbourhood of the focal cell, which is here assumed to be the four nearest neighbors. The term $q_{i \mid j}$ refers to the fraction of cells in state $i$ in the neighbourhood of a cell in state $j$ (also referred to as 'local density'). Figure $1 \mathrm{~A}$ shows the different cell states and the possible transitions between states at each time step. The plant of an occupied cell can die, and it then becomes empty. An empty cell can be colonized by a plant - either a nurse or a protegee - or become degraded. A degraded cell cannot be colonized by a plant but can become empty through regeneration.

Colonization Plants reproduce by spreading seeds in the lattice. The recruitment of a new plant can only be successful if a seed reaches an empty cell, if it germinates and if the sapling reaches the adult stage (Figure 1, see Eq. 1 and 2 for nurses and protegees respectively). An empty cell can receive seeds either from the global dispersal of all the cells occupied by plants in the lattice or from the local dispersal of its neighbouring cells that are occupied by plants. We call $\delta$ the fraction of seeds dispersed globally in the lattice by a given cell occupied by a plant, while $1-\delta$ is the fraction of seeds dispersed in its local neighborhood. The value of $1-\delta$ is typically assumed to be low in our simulations (e.g. .1). Indeed, in drylands, plant species disperse their seeds mainly in their local neighbourhood since many dryland plant species have adaptations to atelechory and even to antitelochory (Fllner and Shmida, 1981, Gutterman, 1994, Peco et al. 2005), meaning that they have developed mechanisms to prevent long-range dispersal.

Competition for resources among the plants present in the lattice can affect the recruitment success of a new plant. The recruitment rate of seeds, summarized in $b$, is assumed to be maximum in the absence of competition for resource, i.e. when there are no other plants in the grid. The recruitment rate of seeds is assumed to decrease with increasing competition for resources $(c)$, i.e. as the fraction of occupied cells $\left(\rho_{+}\right)$in the grid increases (with $\rho_{+}=\rho_{N}+\rho_{P}$, with $\rho_{N}$ and $\rho_{P}$ being respectively the fraction of cells in the grid occupied by the nurse and the protegee). Competition for resources is then assumed to be 'global', i.e. it occurs at the scale of the whole 
landscape, as in previous studies (Kéfi et al. 2007b a, 2011; Schneider and Kéfi, 2016). This is coherent with the the observation that competition typically occurs at a larger spatial scale than facilitation in drylands (e.g. Rietkerk et al. 2000; Rietkerk and van de Koppel, 2008).

To keep the model simple and tractable, the nurse and the protegee species are assumed to be identical, except that the nurse has defences against grazing. Nurse species are therefore not (or less) eaten by grazers than protegees. We choose to stick to the case where the nurse is unpalatable, i.e. not affected by grazing at all. Developing defences against grazers is costly for plants (Lind et al. 2013). In general, defence development occurs at the expense of growth and competitive ability (Yoshida et al. 2004, Lind et al. 2013). We therefore added a cost ( $\gamma$, Eq. 1) for developing grazing defences on nurse recruitment. The nurse has thereby a lower colonization rate than the protegee in the absence of grazing (i.e. $c \rho_{+}-\gamma \leq c \rho_{+}$).

$$
\begin{gathered}
w_{\{0, N\}}=\left(\delta \rho_{N}+(1-\delta) q_{N \mid 0}\right)\left(b-c \rho_{+}-\gamma\right) \\
w_{\{0, P\}}=\left(\delta \rho_{P}+(1-\delta) q_{P \mid 0}\right)\left(b-c \rho_{+}-g(1-p)\right)
\end{gathered}
$$

Indirect facilitation through grazing The recruitment rate of the protegee saplings decreases with grazing rate ( $g$, Eq.22), while the grazing rate can, in turn, be decreased by indirect facilitation $(1-p$, Eq. 2). The strength of indirect facilitation through grazing $(p)$ is a function of the cost of grazing defences $(\gamma)$, thereby assuming a positive relationship between the cost of grazing defences and their efficiency against grazing. $p$ is also function of the fraction of occupied neighbours around the cell in which the protegee sapling is growing $\left(q_{N \mid 0}\right)$. We first define indirect facilitation when only one nurse is present $\left(p_{1 / z}\right)$ in the neighborhood of the protegee sapling, i.e. $q_{N \mid 0}=1 / z, z$ being the number of neighbouring cells around a given cell). We set an exponential relationship between $p_{1 / z}$ and $\gamma$, with $u$ as a shape parameter: $p_{1 / z}=1-$ $e^{-u \gamma}$ (Figure 1 $\mathrm{p}$ ). It corresponds to an accelerating cost of altruism (Le Galliard et al. 2003), meaning that, to some extent, a given increase in the cost of the defence for the nurse will lead to less and less increase of indirect facilitation to the protegee. We then define $p$ for any $q_{N \mid 0}$, i.e. any number of nurse neighbours around a protegee sapling as an exponential relationship, $p=1-e^{-\tau q_{N \mid 0}}$, with $\tau$ as a shape parameter. This means that we made the assumption that the relationship between indirect facilitation and the number of nurse is also decelerating. Finally, the expression of $p$ simplifies to $p=1-e^{-u \gamma z q_{N \mid 0}}$ (the calculus is detailed in supplementary information 22.

Based on the indirect facilitation literature (Burt-Smith et al. 2003, Smit et al. 2006. 2007), we assumed that grazing only affects the recruitment of protegee saplings, unlike previous more generic models, which assumed that grazing affected plant mortality (Kéfi et al. 2007b; Schneider and Kéfi, 2016). Indeed, the sapling stage is often considered to be the most crucial life stage for plants in drylands (Fllner and Shmida 1981; Gutterman, 1994; Chu and Adler, 2015. 
Death Adult plants die at a constant rate $(m)$. The corresponding cells then become empty.

$$
w_{\{N, 0\}}=w_{\{P, 0\}}=m
$$

Degradation Empty cells can become degraded through soil erosion due to wind and water run-off. Degradation is assumed to happen at a constant rate, $d$ :

$$
w_{\{0,-\}}=d
$$

Regeneration Regeneration of a degraded cell can happen spontaneously at a constant rate $(r)$ but it increases with the amount of vegetation in the neighbourhood of the degraded cell because of direct facilitation effect $(f)$. The intensity of direct facilitation is assumed to be the same for nurses and protegees. The transition rate from a degraded to an empty state is maximum when a degraded cell is surrounded by occupied cells, i.e. when $q_{+\mid-}=1$, with $q_{+\mid-}=q_{N \mid-}+q_{P \mid-}$.

$$
w_{\{-, 0\}}=r+q_{+\mid-} f
$$

\subsection{Analysis}

We ran the stochastic cellular automaton (CA) model as spatially-explicit simulations on a two-dimensional grid of cells. In addition, a pair approximation (PA) modeling approach was used for the bifurcation analyses. The PA allows deriving a system of ODE from the transition rules previously described. To limit the set of ODE obtained, the PA approach assumes that the density of cell triplets can be approximated by the density of cell pairs (see van Baalen, 2000, for details). The PA tracks the changes in the densities of both single and pairs of cells (e.g. respectively $\rho_{i}$ and $\rho_{i j}$ for all $i$ and $j$ ). PA models are more general, analytically tractable (van Baalen. 2000), run much faster than the full CA and allow for a deeper exploration of the parameter space.

CA simulations were used to analyze the effects of the combined facilitation types - direct and indirect - on the spatial association between the two plant species. Indeed, the species densities predicted by the PA deviated from the results of the CA for strong indirect facilitation. For example, the CA resulted in $86 \%$ more nurses than the PA for $u=5$ (Figure S1). It seemed therefore more reasonable to use the CA simulations in this case to get more accurate results.

\subsubsection{Cellular automaton simulation}

The cellular automaton was run on a 200 by 200 grid of cells. We assumed that the grid was a torus i.e. it had periodic boundary conditions. This means that the cells of the most right columns were neighbouring the cells of the most left columns. The same principle applied to the down and top cells of the lattice. The locations of the cells initially occupied by a nurse or a protegee adult plant were drawn randomly. The 

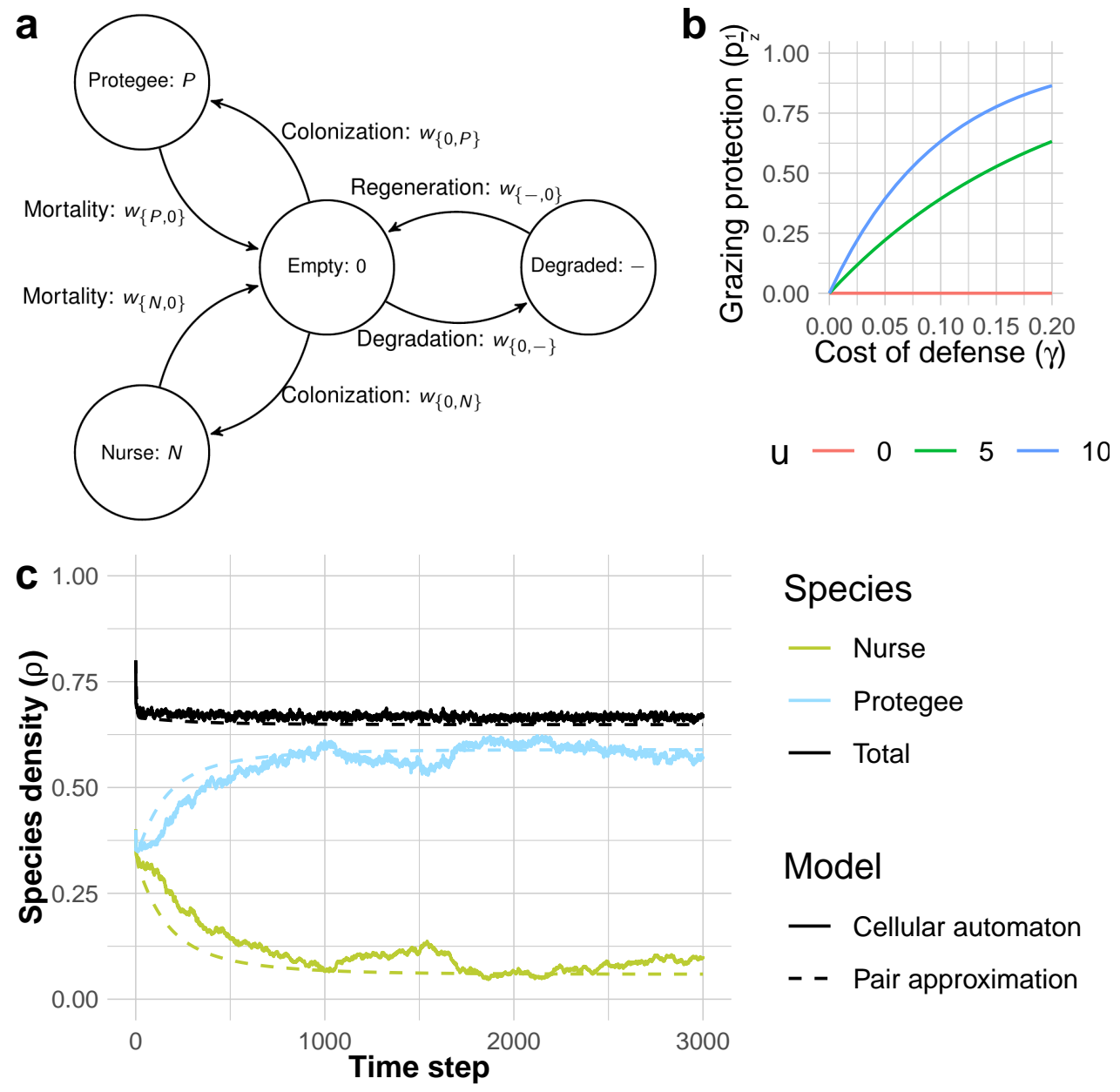

\section{Species}

- Nurse

- Protegee

- Total

Model

Cellular automaton

- - Pair approximation

Fig. 1 Model details. (A) Schematic representation of the possible transitions between cell states. (B) Relationship between the grazing protection provided by one nurse $\left(q_{N \mid 0}=\frac{1}{z}\right)$ and the cost of the nurse to develop defences. (C) Example of a numeric simulation comparing the output of the pair approximation model and of the cellular automaton model. Parameters used: $b=1, g=0.13, u=5$; see Table 1 for the other parameter values.

CA simulations were initiated with a vegetation cover of .80 , i.e. $\rho_{N}=\rho_{P}=.4$. The simulations were run until the density of each species reached a stability criterion or when both species became extinct. Each 200 time units, we computed the average 1 density of both species over the 200 last time units. Starting at 400 and each 200 time units, we computed the absolute density difference for both species between two subsequent averages (for example, from 0 to 199 and from 200 to 399 time units). We considered that stability was reached when the former absolute difference fell below 0.005 , this threshold being chosen after careful examination of simulation time series. 
When the stability criterion was reached, we kept the average density of each species over the last 300 time steps of the simulations.

The clustering between species was computed following van Baalen (2000). $C_{i, j}$ compared the average number of $i$ cells in the neighbourhood of $j$ cells, $q_{i \mid j}$, to the expected number of $i$ neighbours expected by chance, i.e. $\rho_{i}$. Values of $C_{i, j}$ inferior and superior to 1 indicate that cells $i$ and $j$ are found next to each other respectively less and more frequently than expected by chance To link our study with empirical investigations (Bisigato et al., 2005; Graff and Aguiar, 2011), we also recorded the average number of protegee cells in the neighbourhood of nurse cells (i.e. $q_{P \mid N}$ ).

$$
\begin{aligned}
C_{\{i, j\}} & =\frac{q_{i \mid j}}{\rho_{i}} \\
C_{\{+,+\}} & =\frac{q_{+\mid+}}{\rho_{+}} \\
C_{\{N, P\}} & =\frac{q_{P \mid N}}{\rho_{P}}=\frac{q_{N \mid P}}{\rho_{N}}
\end{aligned}
$$

\subsubsection{Pair approximation model analysis}

The pair approximation model contains ten ordinary differential equations (ODE) describing the dynamics of the cell pairs $\left(\rho_{N N}, \rho_{N 0}, \rho_{N P}, \rho_{N-}, \rho_{P P}, \rho_{P 0}, \rho_{P-}, \rho_{00}, \rho_{0-}, \rho_{--}\right.$ with $\left.\rho_{\sigma \sigma^{\prime}}=\rho_{\sigma^{\prime} \sigma}\right)$ as well as four equations describing the singleton variables $\left(\rho_{N}, \rho_{P}, \rho_{0}, \rho_{-}\right)$. Thanks to five conservation equations (supplementary information 3), we can reduce the system of equations to $9(10+4-5=9)$ equations. We chose to retain the following variables: $\rho_{N N}, \rho_{N P}, \rho_{N-}, \rho_{P P}, \rho_{P-}, \rho_{--}, \rho_{N}, \rho_{P}, \rho_{-}$. The system of ODE is displayed in supplementary information 3.1

The baseline model parametrization was done according to previous versions of the model (Table 1) (Kéfi et al., 2007b; Schneider and Kéfi, 2016). The simulations were run for 10000 time units maximum. The simulations were stopped either when 10000 time steps were reached or when the sum of the absolute values of the derivatives fell below $10^{-} 10$, meaning that the system had reached a steady state. We ensured the consistency of the parameter space explored by checking for the absence of negative densities and numerical errors.

The simulations were started with two initial vegetation covers: high and low (respectively .8 and .01, one half for each of the two species). The initial density of the cell pairs was defined as the product of initial single cell density, i.e. for example $\rho_{N N}=\rho_{N} * \rho_{N}$ and $\rho_{N P}=\rho_{N} * \rho_{P}$. The low initial vegetation cover allows testing whether a few individuals can colonize the system. From a mathematical point of view, starting from a low cover represents a perturbation of the desert state, allowing to see if it is stable. We wanted to see if the simulation outcomes would be different for the two initial vegetation covers.

At the end of each simulation of the PA model, we kept the average species densities over the 10 last time units. This number is low because the simulations stopped when the system reached stability and the PA model did not include any stochasticity. A species was considered extinct if its densities was below .01 at the end of the simulation. This was repeated for all parameter combinations studied. 
Table 1 Parameter definition and values of the model. Based on Kéfi et al. (2007b); Schneider and Kéfi (2016.

\begin{tabular}{|c|c|c|}
\hline Symbol & Ecological meaning & Default values \\
\hline$\delta$ & $\begin{array}{l}\text { Fraction of seeds produced by an occupied cell that is globally dispersed, i.e. all } \\
\text { over the grid }\end{array}$ & 0.1 \\
\hline$b$ & $\begin{array}{l}\text { Maximum recruitment rate of a new plant on an empty cell, realized in a system } \\
\text { without vegetation. } b \text { is assumed to reflect the environmental quality. }\end{array}$ & 0.8 \\
\hline$c$ & Competitive effect of vegetated cells on the establishment of new individuals & 0.2 \\
\hline$\gamma$ & $\begin{array}{l}\text { Additional mortality rate of seedlings due to the development of defence against } \\
\text { grazing, i.e. cost of the defenses to nurse seedlings }\end{array}$ & 0.1 \\
\hline$g$ & $\begin{array}{l}\text { Additional mortality rate of protegee seedlings due to grazing, realized in ab- } \\
\text { sence of indirect facilitation through grazing }\end{array}$ & 0.1 \\
\hline$p_{1 / z}$ & $\begin{array}{l}\text { Indirect facilitation through grazing; Decrease in the mortality rate due to grazing } \\
\text { experienced by the protegee seedlings when one nurse is present in its neighbor- } \\
\text { hood. }\end{array}$ & $0 ; .39$ \\
\hline$u$ & $\begin{array}{l}\text { Parameter of the exponential relationship between the protection against grazing } \\
\text { provided by one nurse plant and the cost } \gamma \text { of the protection for the nurse: } p_{\frac{1}{z}}= \\
1-e^{-u \gamma}\end{array}$ & $0 ; 5$ \\
\hline$m$ & Mortality rate of adult plants. Life expectancy: $\frac{1}{m}$ & 0.1 \\
\hline$d$ & Degradation rate of empty sites $(0)$ & 0.1 \\
\hline$r$ & Spontaneous regeneration rate of degraded cells into fertile empty cells & 0.01 \\
\hline$f$ & $\begin{array}{l}\text { Direct facilitation; Maximum facilitative effect of the neighborhood on the re- } \\
\text { generation rate of degraded cells into fertile empty cells, realized when all near- } \\
\text { est neighbors sites are occupied by vegetation }\end{array}$ & 0.9 \\
\hline$z$ & Number of cells in the direct neighbourhood of a focal cell & 4 \\
\hline
\end{tabular}

We defined a stable state as a unique community composition: either desert (no species maintained), protegee alone, nurse alone or coexistence, meaning that both species are maintained in the landscape at equilibrium. For some parameter combinations, the stable states reached at the end of the simulations differed between the two initial vegetation covers tested, i.e. the low and high initial vegetation covers. This is a sign that the system exhibits alternative stable states, or 'bistability' for this parameter combination.

The model was implemented in $\mathrm{R}$ (R Core Team, 2017) with the simecol package (Petzoldt and Rinke, 2007). The PA model was numerically solved with the deSolve (Soetaert et al. 2010) package. We used the 1soda solver, which adapts dynamically the resolution of the numerical integration. The implementation of the model and the code used to analyze the simulations are available as a $\mathrm{R}$ package structure on github (github.com/alaindanet/indirect_facilitation_model).

\section{Results}

Independently of the species present in the landscape, a decrease in environmental quality always leads to a decrease in vegetation cover until the ecosystem reaches a 


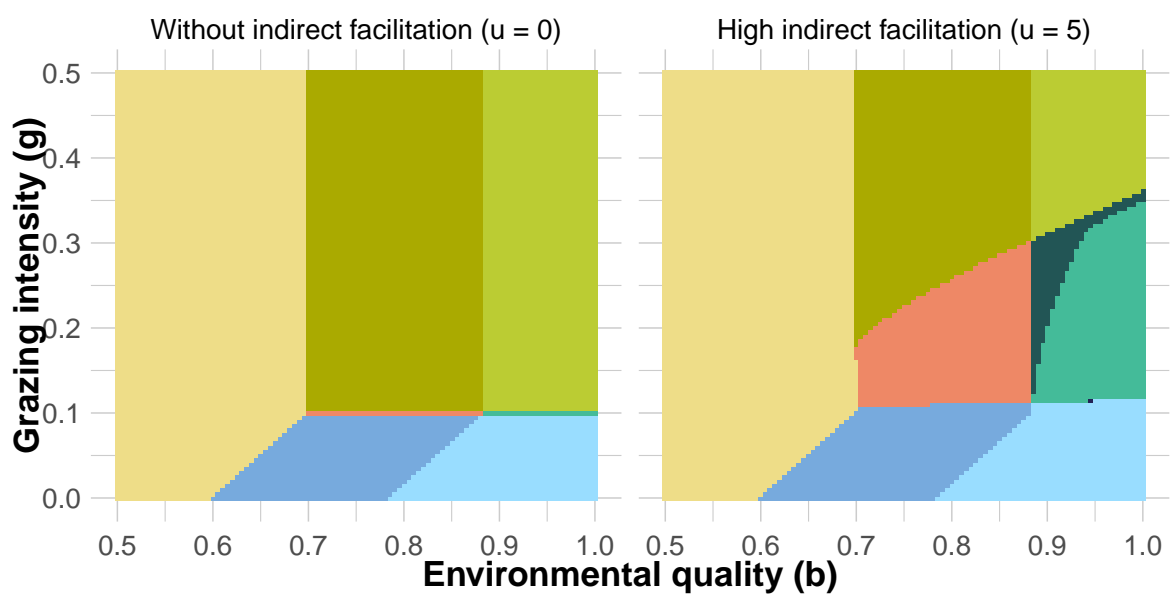

Stable states

\begin{tabular}{lll} 
Coexistence & Coexistence / Protegee & Nurse / Desert \\
Coexistence / Desert & Desert & Protegee \\
\hline Coexistence / Nurse & Nurse & Protegee / Desert
\end{tabular}

Fig. 2 State diagram of the system along a gradient of environmental quality (parameter $b$ reflecting e.g. total rainfall) and of grazing intensity $(g)$, in the absence (left panel, $u=0$ ) and in the presence (right panel, $u=5$ ) of indirect facilitation. Simulation results from the pair approximation model. For the parameter values chosen $(u=5$ and $\gamma=0.1)$, the grazing effect decreases by $39 \%$ for a protegee sapling which is surrounded by one nurse plant. The parameter values are displayed in Table 1 The resolution of $b$ and $g$ is .005. For each parameter combination, the type of equilibrium reached is indicated by a different color (see legends). For some parameter combinations, there are two possible stable states coexisting depending on the initial condition of cover with which the simulation stated (e.g. 'Coexistence / Desert' in the legend indicates that for this combination of parameter values, the ecosystem can be either a desert or vegetated with nurses and protegees coexisting with each other).

tipping point at which it eventually drops in a discontinuous way from a vegetated to a desert state (i.e. a state where there was no vegetation left in the landscape; Figure 2). Once the transition to a desert state occurs (Figure 3. sand color), the environmental quality has to be restored to higher values than before the shift to recover a vegetated state (Figure 3 , light and dark blue colors), meaning that the ecosystem exhibits hysteresis. This is due to the fact that at intermediate values of environmental quality, the system shows bistability, i.e. there is a range of environmental quality values for which the system can either be vegetated or a desert (either "Coexistence / Desert", "Nurse / Desert" or "Protegee / Desert", Figure 2). The presence of indirect facilitation does not affect the location of the tipping points along the environmental quality gradient at a given grazing level (Figure 2 and 3 ).

At low grazing levels, only the protegee maintains itself (Figure 2, light blue colors; "Protegee", "Protegee / Desert"). In the absence of indirect facilitation, there 
is a thin area of coexistence of the nurse and the protegee $(g=.1$, Figure 2, left panel; "Coexistence", "Coexistence / Desert"), which occurs when the colonization rates of the nurse and the protegee are exactly identical (i.e. for $g=\gamma=.1$, meaning that $w_{\{0, N\}}=w_{\{0, P\}}$, see Eq.1 and 2). Higher grazing intensities lead to the survival of the nurse only (Figure 2 , "Nurse", "Nurse / Desert"). In the presence of indirect facilitation, the area of stable coexistence between the nurse and the protegee increases considerably (Figure 2 right panel; "Coexistence", "Coexistence / Desert", "Coexistence / Nurse", "Coexistence / Protegee"). It is noticeable that, with indirect facilitation, the nurse is excluded by the protegee for $g=.1$, i.e. at a value for which the nurse maintains itself in the case without indirect facilitation. This suggests that, with indirect facilitation, a cost for the nurse emerged in the model from competition despite the fact the two species are considered to be equal competitors in the model.

Overall, there are more configurations of alternative stable states with indirect facilitation than without (9 versus 7), suggesting an emergent complexity in the presence of indirect facilitation. Considering the stable states along a gradient of environmental gradient ( $b$, from high to low) for a grazing intensity of .25 , the ecosystem goes successively through a "Coexistence" state, a "Coexistence / Nurse" bistability area , a "Coexistence / Desert" bistability area , a "Nurse / Desert" bistability area and a "Desert" state (Figure 2, right panel; Figure 3, right column for details).

The densities of each of the two species are lower in the presence of the nurse than when alone, i.e as soon as coexistence occurs (Fig 3 D vs F, H vs I and K vs L). This occurs because the total vegetation cover remains constant for a given environmental quality value $(b)$, since the model assume that the scale of competition for resources $(c)$ is global and that competition intensity scales linearly with the total density of vegetation $\left(\rho_{+}\right)$. Moreover, as expected, when both species is present, protegees tend to have higher densities in the presence than in the absence of indirect facilitation ( $\mathrm{Fig} 3 \mathrm{D}$ vs E, G vs $\mathrm{H}$ and $\mathrm{J}$ vs $\mathrm{K}$ ). Conversely, the nurse density is lower with than without indirect facilitation (Figure $3 \mathrm{D}$ vs $\mathrm{E}, \mathrm{G}$ vs $\mathrm{H}$ and $\mathrm{J}$ vs K). Indeed, as soon as the protegees are present in the landscape, the cover of nurses decreases because of the competition for resources. At the same time, the nurse density exhibits bimodal high cover values when indirect facilitation is present $(\mathrm{Fig} 3 \mathrm{H}, \mathrm{K}$; middle column). For intermediate and high values of both grazing intensity $(g=[.25 ; 3])$ and environmental quality $(b \simeq[.88 ; .93])$, the nurse density can take two different paths depending on whether the protegee is extinct or present ("Coexistence / Nurse" bistability area).

Looking at the bifurcation diagrams of each of the two species taken individually, indirect facilitation affects the catastrophic behavior of the protegee along the aridity gradient (Figure 3). Trivially, without indirect facilitation (Figure 3 A, D, G, J; left column), each species totally dominates successively along the grazing intensity gradient (except at $g=.1$ where the two species are identical) and the position of the tipping point to desertification does not change. The protegee alone in the landscape shows a catastrophic behavior for all grazing intensity values (Figure 3 C, F, I, L; right column). As grazing intensity increases, the tipping point at which the protegee 
density shifts from high to no cover and conversely (i.e. from no to high cover), occurs at higher environmental quality values, indicating that the ecosystem collapses and recovers earlier when grazing is higher. At moderate to high grazing intensities (Figure 3 I, L; right column), the shift from high to low cover becomes irreversible, i.e., the protegee cannot not recolonize the system even if the environmental quality is high.

In the presence of the nurse and of indirect facilitation (Figure $3 \mathrm{H}, \mathrm{K}$; middle column), the density of the protegee shows a linear decrease from high to low cover instead of an abrupt shift at a tipping point. However, the reverse transition (from low to high cover) still exhibits a tipping point. Unlike when the protegee is alone (Figure 3 I, L; right column), the transition of the protegee density from low to high cover is possible and happens at moderately high environmental quality values. Overall, our results showed that indirect facilitation allows for coexistence of the two species at intermediate and high grazing levels. Another effect of indirect facilitation through grazing is a modification of the catastrophic behavior of the protegee. Indirect facilitation progressively transforms the transition of the protegee to extinction from a discontinuous to a continuous one, thereby making the transition reversible.

Overall, the inter-specific clustering (i.e. between the nurse and the protegee, Figure 4 C, D) and the total vegetation clustering (i.e. ignoring the species identity, Figure 4 E, F) are two to four times higher than expected by chance. The strength of indirect and direct facilitation has no or little effect on inter-specific and total vegetation clustering and is driven by global dispersal, i.e. the value of $\delta$ (Figure 4 C, D, E, F). Total vegetation clustering decreases from 4.5 to 4.0 with an increase in the fraction of global dispersal from 0 to 1 (Figure 4 C, D), whereas inter-specific clustering increases from about 2.5 to 4 with the same increase in global dispersal. The average number of protegee cells surrounding nurse cells increases with increasing global dispersal but also with the strength of both facilitation types, indirect (Figure 4 $\mathrm{G}$ ) and direct (Figure $4 \mathrm{H}$ ). However, the effect is greater for indirect (from 0 to 1.61 protegee cells) than for direct facilitation (from 0.08 to 1.03 protegee cells). For intermediate global dispersal values $(\delta \simeq 0.5$ ), the effect of indirect facilitation on the average number of protegee cells surrounding nurse cells is two times higher than the effect of direct facilitation.

\section{Discussion}

Previous modelling studies on catastrophic shifts in drylands have largely oversimplified the role played by community composition and plant functional types in shaping ecosystem dynamics. Our study paves the way for reconciling approaches from community ecology with those from catastrophic shifts theory in drylands. We expanded on previous dryland vegetation models (Kéfi et al., 2007b, Schneider and Kéfi. 2016) by integrating two species, a nurse and a protegee, and two types of facilitation that are common in dryland ecosystems, direct and indirect. In particular, we integrated indirect facilitation, i.e. an indirect interaction between two plant species, modulated by a third component, here grazing. We showed with a generic model that adding 


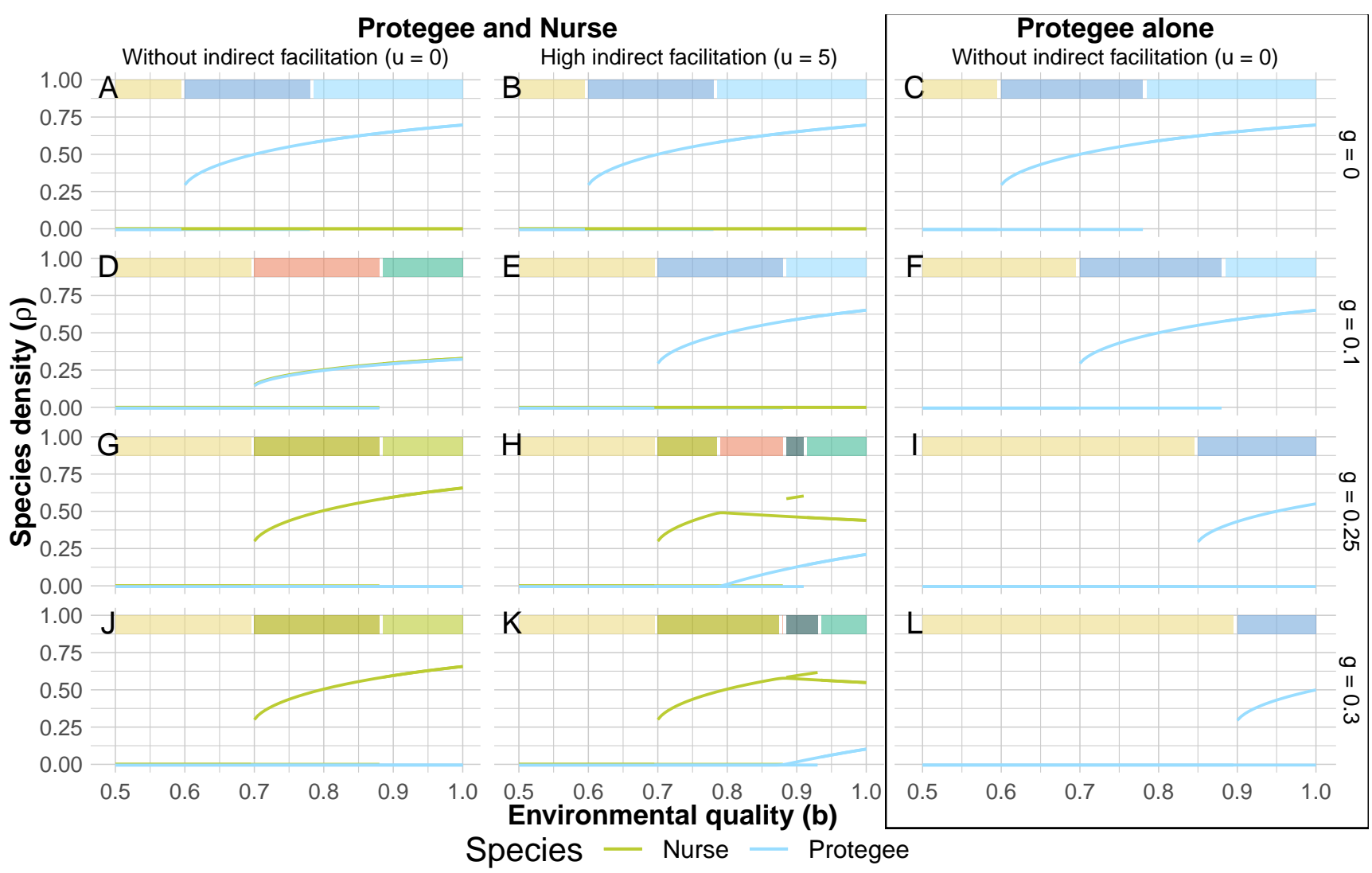

Fig. 3 Equilibrium densities of the nurse and the protegee along a gradient of environmental quality with the protegee and the nurse present (left and middle column, A, B, D, E, G, H, J, K) and the protegee alone at the beginning of the simulation (right column, C, F, I, L). Simulations without (left column, A, D, G, $\mathrm{J}, u=0$ ) and with (middle column, $u=5$ ) indirect facilitation for different levels of grazing intensity (g). The top bars indicate the type of stable states. See Figure 2 for color legend. Simulation results from the pair approximation model. See the legend of Figure 2 for the parameter values used for the initial covers of each species.

indirect facilitation through grazing from a nurse to a protegee can create stable coexistence between two species which would otherwise exclude each other. Our result also suggest that indirect facilitation through grazing may modify the type of ecosystem transition to desertification. Finally, we, surprisingly, did not find any effect of indirect facilitation through grazing on inter-specific or total vegetation clustering.

\subsection{Species coexistence}

In agreement with our first expectation, we found that indirect facilitation through grazing can create stable coexistence between two competing species. This result contributes to improving our understanding of plant coexistence in drylands. First, even if interspecific interactions are globally negative in the community and if there 
is dominance of one of the species (of either the protegee or the nurse), our results suggest that two species in competition can coexist if there is indirect facilitation between them.

One interpretation of this coexistence is that indirect facilitation creates heterogeneity in the spatial distribution of grazing pressure on the protegee saplings, resulting in a spatially heterogeneous colonization rate of the protegee in the landscape. Previous studies have shown that spatial heterogeneity in environmental conditions, in mortality rate or in competition could lead to stable coexistence between species in competition (Muko and Iwasa, 2000, Chesson, 2000a b). Chesson (2000a b) demonstrated that this is even the case in the presence of a competitive hierarchy between species. In line with these previous studies, our results showed that heterogeneity in the mortality rate - the consumption rate of protegee saplings in our study - can lead to the stable coexistence of two species in competition. Pacala and Crawley (1992) have furthermore shown that spatial variation of predator abundance and apparent competition can also create the conditions for stable coexistence. Our results contribute to the previous literature by showing that stable coexistence between competing species can emerge in cases where the spatial heterogeneity is created by one of the competing species itself, here the nurse plant.

We suggest that the coexistence between the nurse and the protegee is stabilized by a negative feedback loop. Since the nurse density decreases as the protegee density increases, the amount of grazing refuges decreases as well, which results in a decrease in the protegee density. In the same way, the increase in nurse density increases the occurrence of grazing refuges, i.e. sites where the protegee will outcompete the nurse. This mechanism appears to be similar to that modelled in a previous studies. Gross (2008) defined positive interactions as dependent of species density. He showed that coexistence can also be achieved by a negative feedback loop. The nurse and protegee densities determine the number of grazing refuges, which determines the competitive hierarchy between the protegee and the nurse species. Then, even in absence of an explicit spatial heterogeneity, i.e. mean field approximation, we should observe coexistence as in the study of Gross (2008).

\subsection{Facilitation cost}

We found that indirect facilitation through grazing can be costly for the nurse, in line with our second expectation. In the presence of indirect facilitation, the nurse is excluded by the protegee at higher grazing intensities than in the absence of indirect facilitation. Indirect facilitation through grazing increases the density of the protegee until it reaches a sufficient density to progressively exclude the nurse. The question of the nurse cost is relatively new in plant facilitation research (Schöb et al., 2014, García et al. 2016; Dangles, 2019). Previous studies showed that a beneficiary species can have a negative effect on the reproductive output of its benefactor (Schöb et al. 2014, García et al. 2016). In our case, rather than focusing on the individual level, we investigated the effect of facilitation at the landscape level. In this light, this study adds a population perspective to the cost of being a nurse plant. 
Our model shows that when the spatial scale of competition is large, there is a cost for the nurse in terms of density since it maintains a competitor in the landscape, increasing competition for resources. For the sake of simplicity, we considered in the model that the cost for developing defences was fixed. Further research could incorporate this cost in asymmetric competition between the nurse and the protegee (i.e. different $c$ values for each species), according to the competition/defence trade off (Bazzaz et al., 1987; Viola et al. 2010). Then, the cost would be density dependent as in the study of Dangles (2019). Our results on facilitation cost indicates that a better understanding of the effects of facilitation on the benefactor necessitates to scale up studies from the individual plant to the community and ecosystem level.

\subsection{Ecosystem dynamics}

Our results indicate that indirect facilitation, through its effect on species coexistence, increases the complexity of the ecosystem dynamics along grazing and aridity gradients. This is related to the fact that, in our model, dryland ecosystems exhibit catastrophic transitions to desertification, such transitions being typical of dryland ecosystems but also of other ecological systems (Scheffer et al., 2001). In the presence of indirect facilitation, only the nurse can recover from low vegetation cover, while both species coexist and are abundant at high cover (i.e. before the collapse to the desert state). The latter was true for a large range of grazing and aridity intensities. This suggests that the community composition of the ecosystem is not resilient when indirect facilitation is present. Therefore, taking indirect interactions into consideration could enhance our understanding of the resilience of species composition and ecosystem properties in drylands. If a perturbation or a change in environmental condition affect species composition, one can expect key ecosystem properties, such as productivity and resilience to upcoming perturbations, to be affected as well.

Our results show that there are situations where, even if ecosystem properties such as vegetation cover recover, the community composition may not recover. This observation can have important implications, notably in restoration ecology. Starting from low vegetation cover and after having restored the environmental condition preceding the ecosystem shift to a degraded state, it might be difficult to restore the community composition that was known before the collapse of the ecosystem.

Looking closer at the species dynamics, our results showed that indirect facilitation can change the catastrophic nature of the transition of the protegee to extinction, transforming it from a discontinuous to a gradual transition. Nonetheless, despite the gradual transition toward a desert state, the reverse transition, i.e. the transition from low to high cover, is not gradual. This result has important conceptual consequences. By favoring the presence of a nurse that provides indirect facilitation through grazing, one can expect that a possible loss of the protegee in the landscape will be more easily to reverse. Here, in particular, indirect facilitation has a different effect from direct facilitation. Unlike direct facilitation, which creates a positive feedback at the landscape level enhancing catastrophic shifts, indirect facilitation through grazing seems to decrease the irreversibility of catastrophic shifts. 
Our model assumes that the nurse and the protegee provide the same strength of direct facilitation, meaning that the two species have the same effect on the positive feedback which generates catastrophic shifts in the model. To our knowledge, there are no empirical evidence about if and how the strength of direct facilitation is correlated to the strength of indirect facilitation provided by a given species. A given nurse could for example be a "super facilitator", i.e. providing strong direct and strong indirect facilitation. There could also be trade-offs between both types of facilitation, where a nurse would provide weak direct but strong indirect facilitation, for example. Because the strength of the positive feedback loop between generating catastrophic shifts depends on the strength of direct facilitation, either of these two cases is expected to have important consequences on the ecosystem dynamics along stress gradients. Further research is needed to improve our understanding of the effects of different types of facilitation on dryland ecosystem dynamics.

\subsection{Species clustering}

Contrary to our expectation, we found that the clustering between the nurse and the protegee was not driven by the strength of facilitation but by dispersal limitation. Our results showed however that the strength of indirect facilitation and the fraction of global dispersal jointly drive the number of protegees in the neighbourhood of the nurse, in agreement with empirical results (Bisigato et al., 2005: Graff and Aguiar, 2011). By maintaining favorable sites in their neighborhood, nurse species allow protegees to increase in abundance locally and globally in the landscape. At the landscape scale, protegees and nurses do not become more clustered because as the average number of protegees in the neighbourhood of a nurse increases, the overall density of protegees increases as well. Then, the probability of finding a protegee next to a nurse by chance increases conjointly with the average number of protegee in the neighborhood of nurse plant. This result challenges the intuitive expectation that an increase in positive interaction intensity should result in a higher nurse-protegee clustering. In this model, the overall positive co-occurence that we found was driven by the fact that, at any given moment in time, a large part of the landscape cannot be colonized because it is in a degraded state, which is typical of drylands (Rietkerk et al. 2004, Kéfi et al., 2007a). The sites suitable for recruitment are often created by direct facilitation. Vegetation clustering in drylands is thus strongly constrained by direct facilitation, and this may mask the effect of indirect facilitation through grazing on the clustering between the nurse and the protegee.

\section{Conclusion}

Our study highlights that indirect facilitation through grazing can promote species coexistence in drylands, while nonetheless being costly for the nurse. We showed that indirect facilitation by a nurse changes the way the protegee transitions to extinction, making this transition more reversible. We also found that, despite the fact that indirect facilitation strength increases the protegee density, this effect is not translated 
into higher species clustering. Our work is a step toward integrating different interaction types and species strategies in models of dryland vegetation dynamics. Our work opens perspectives about the study of both positive interactions and catastrophic shifts in drylands. While positive interactions are largely absent from the conceptual framework of species coexistence, future studies should include positive interactions and broaden the types of interactions considered (Kéfi et al. 2016). With this study, we make a case for the importance of including species' functional trait diversity, for example dispersal, resource management strategies and palatability, into ecological theory.

Author contribution AD, FDS and SK contributed to the study conception and design. Model development and analysis were performed by AD. The first draft of the manuscript was written by $\mathrm{AD}$ and all authors commented on previous versions of the manuscript. All authors read and approved the final manuscript.

Funding The research study has received a funding from the European Union Seventh Framework Programme (FP7/2007-2013) under grant agreement no. 283068 (CASCADE project). The authors declare that they have no conflict of interest.

Acknowledgements We are grateful to the two anonymous reviewers who have helped us improve the manuscript. The analysis of the model benefited from the Montpellier Bioinformatics Biodiversity platform supported by the LabEx CeMEB, an ANR "Investissements d'avenir" program (ANR-10-LABX-04-01).

\section{References}

Anthelme F, Dangles O (2012) Plant-plant interactions in tropical alpine environments. Perspectives in Plant Ecology, Evolution and Systematics 14(5):363-372, DOI 10.1016/j.ppees.2012.05.002, URL http://linkinghub.elsevier.com/ retrieve/pii/S1433831912000352

Anthelme F, Michalet R (2009) Grass-to-tree facilitation in an arid grazed environment (Aïr Mountains, Sahara). Basic and Applied Ecology 10(5):437-446, DOI 10.1016/j.baae.2008.10.008, URL http://linkinghub.elsevier.com/ retrieve/pii/S1439179108000947

Aschehoug ET, Brooker R, Atwater DZ, Maron JL, Callaway RM (2016) The Mechanisms and Consequences of Interspecific Competition Among Plants. Annual Review of Ecology, Evolution, and Systematics 47(1):263-281, DOI 10.1146/annurev-ecolsys-121415-032123, URL http://www . annualreviews . org/doi/10.1146/annurev-ecolsys-121415-032123

Atsatt PR, O’Dowd DJ (1976) Plant defense guilds. Science 193(4247):24-29, URL http://www.planta.cn/forum/files_planta/1452_1196055247.pdf_ 462.pdf

van Baalen M (2000) Pair Approximations for Different Spatial Geometries. In: The Geometry of Ecological Interactions: Simplifying Spatial Complexity, Simplifying Spatial Complexity, Cambridge University Press, International Institute for Applied Systems Analysis 
Bazzaz FA, Chiariello NR, Coley PD, Pitelka LF (1987) Allocating Resources to Reproduction and Defense. BioScience 37(1):58-67, DOI 10.2307/1310178, URL http://bioscience.oxfordjournals.org/cgi/doi/10.2307/1310178

Bertness MD, Callaway R (1994) Positive interactions in communities. Trends in ecology \& evolution 9(5):191-193, URL http://www.sciencedirect.com/ science/article/pii/0169534794900884

Bisigato AJ, Bertiller MB, Ares JO, Pazos GE (2005) Effect of grazing on plant patterns in arid ecosystems of Patagonian Monte. Ecography 28(5):561-572, URL http://onlinelibrary.wiley.com/doi/10.1111/j . 2005.0906-7590.04170.x/full

Bruno JF, Stachowicz JJ, Bertness MD (2003) Inclusion of facilitation into ecological theory. Trends in Ecology \& Evolution 18(3):119-125, URL http://www . sciencedirect.com/science/article/pii/S0169534702000459

Bulleri F, Bruno JF, Silliman BR, Stachowicz JJ (2016) Facilitation and the niche: implications for coexistence, range shifts and ecosystem functioning. Functional Ecology 30(1):70-78, DOI 10.1111/1365-2435.12528, URL http://doi . wiley.com/10.1111/1365-2435.12528

Burt-Smith GS, Grime JP, Tilman D (2003) Seedling resistance to herbivory as a predictor of relative abundance in a synthesised prairie community. Oikos 101(2):345353, DOI 10.1034/j.1600-0706.2003.11052.x, URL http://onlinelibrary. wiley.com/doi/10.1034/j.1600-0706.2003.11052.x/abstract

Callaway RM (2007) Positive interactions and interdependence in plant communities. Springer, Dordrecht

Cardinale BJ, Palmer MA, Collins SL (2002) Species diversity enhances ecosystem functioning through interspecific facilitation. Nature 415(6870):426-429, DOI 10.1038/415426a, URL http://www.nature.com/nature/journal/v415/ n6870/full/415426a.html

Cavieres LA, Brooker RW, Butterfield BJ, Cook BJ, Kikvidze Z, Lortie CJ, Michalet R, Pugnaire FI, Schöb C, Xiao S, Anthelme F, Björk RG, Dickinson KJM, Cranston BH, Gavilán R, Gutiérrez-Girón A, Kanka R, Maalouf JP, Mark AF, Noroozi J, Parajuli R, Phoenix GK, Reid AM, Ridenour WM, Rixen C, Wipf S, Zhao L, Escudero A, Zaitchik BF, Lingua E, Aschehoug ET, Callaway RM (2014) Facilitative plant interactions and climate simultaneously drive alpine plant diversity. Ecology Letters 17(2):193-202, DOI 10.1111/ele.12217, URL http: //dx.doi.org/10.1111/ele.12217

Chesson P (2000a) General Theory of Competitive Coexistence in Spatially-Varying Environments. Theoretical Population Biology 58(3):211-237, DOI 10.1006/tpbi. 2000.1486, URL http://www.sciencedirect.com/science/article/pii/ S0040580900914862

Chesson P (2000b) Mechanisms of Maintenance of Species Diversity. Annual Review of Ecology and Systematics 31(1):343-366, DOI 10.1146/annurev.ecolsys. 31.1.343, URL https://doi.org/10.1146/annurev.ecolsys.31.1.343

Chu C, Adler PB (2015) Large niche differences emerge at the recruitment stage to stabilize grassland coexistence. Ecological Monographs 85(3):373-392, URL http://onlinelibrary.wiley.com/doi/10.1890/14-1741.1/full 
Couteron P, Anthelme F, Clerc M, Escaff D, Fernandez-Oto C, Tlidi M (2014) Plant clonal morphologies and spatial patterns as self-organized responses to resourcelimited environments. Philosophical Transactions of the Royal Society A: Mathematical, Physical and Engineering Sciences 372(2027):20140102

Danet A, Kéfi S, Meneses RI, Anthelme F (2017) Nurse species and indirect facilitation through grazing drive plant community functional traits in tropical alpine peatlands. Ecology and Evolution 7(24):11265-11276, DOI 10.1002/ece3.3537, URL http://doi.wiley.com/10.1002/ece3.3537

Danet A, Anthelme F, Gross N, Kéfi S (2018) Effects of indirect facilitation on functional diversity, dominance and niche differentiation in tropical alpine communities. Journal of Vegetation Science

Dangles O (2019) A dynamic model of facilitation on environmental stress gradients. Oikos 128(8):1206-1214, DOI 10.1111/oik.06136, URL https:// onlinelibrary.wiley.com/doi/abs/10.1111/oik.06136

Filazzola A, Lortie CJ (2014) A systematic review and conceptual framework for the mechanistic pathways of nurse plants: A systematic review of nurse-plant mechanisms. Global Ecology and Biogeography 23(12):1335-1345, DOI 10.1111/geb. 12202, URL http://doi .wiley.com/10.1111/geb.12202

Fllner S, Shmida A (1981) Why are adaptations for long-range seed dispersal rare in desert plants? Oecologia 51(1):133-144, URL http://link.springer.com/ article/10.1007/BF00344663

García MC, Bader MY, Cavieres LA (2016) Facilitation consequences for reproduction of the benefactor cushion plant Laretia acaulis along an elevational gradient: costs or benefits? Oikos 125(3):434-442, URL http://onlinelibrary . wiley . com/doi/10.1111/oik.02592/full

Graff P, Aguiar MR (2011) Testing the role of biotic stress in the stress gradient hypothesis. Processes and patterns in arid rangelands. Oikos 120(7):10231030, DOI 10.1111/j.1600-0706.2010.19059.x, URL http://doi.wiley.com/ $10.1111 / \mathrm{j} .1600-0706.2010 .19059 . \mathrm{x}$

Graff P, Aguiar MR, Chaneton EJ (2007) Shifts in positive and negative plant interactions along a grazing intensity gradient. Ecology 88(1):188-199, URL http://www.esajournals .org/doi/abs/10.1890/0012-9658(2007) 88\%5B188:SIPANP $\%$ D2.0.C0\%3B2

Gross K (2008) Positive interactions among competitors can produce speciesrich communities. Ecology Letters 11(9):929-936, DOI 10.1111/j.1461-0248. 2008.01204.x, URL http://doi.wiley.com/10.1111/j.1461-0248.2008. $01204 . \mathrm{x}$

Gutterman Y (1994) Strategies of seed dispersal and germination in plants inhabiting deserts. The Botanical Review 60(4):373-425, DOI 10.1007/BF02857924, URL http://dx.doi.org/10.1007/BF02857924

Kikvidze Z, Brooker RW, Butterfield BJ, Callaway RM, Cavieres LA, Cook BJ, Lortie CJ, Michalet R, Pugnaire FI, Xiao S, Anthelme F, Björk RG, Cranston BH, Gavilán RG, Kanka R, Lingua E, Maalouf JP, Noroozi J, Parajuli R, Phoenix GK, Reid A, Ridenour WM, Rixen C, Schöb C (2015) The effects of foundation species on community assembly: a global study on alpine cushion plant communities. Ecology 96(8):2064-2069, DOI 10.1890/14-2443.1, URL http: 
//doi.wiley.com/10.1890/14-2443.1

68 Kéfi S, Rietkerk M, Alados CL, Pueyo Y, Papanastasis VP, ElAich A, de Ruiter PC (2007a) Spatial vegetation patterns and imminent desertification in Mediterranean arid ecosystems. Nature 449(7159):213-217, DOI 10.1038/nature06111, URL http://www .nature.com/doifinder/10.1038/nature06111

Kéfi S, Rietkerk M, van Baalen M, Loreau M (2007b) Local facilitation, bistability and transitions in arid ecosystems. Theoretical Population Biology 71(3):367379, DOI 10.1016/j.tpb.2006.09.003, URL http://www.sciencedirect.com/ science/article/pii/S0040580906001250

Kéfi S, Eppinga MB, de Ruiter PC, Rietkerk M (2010) Bistability and regular spatial patterns in arid ecosystems. Theoretical Ecology 3(4):257269, DOI 10.1007/s12080-009-0067-z, URL http://link. springer . com/10 . 1007/s12080-009-0067-z

Kéfi S, Rietkerk M, Roy M, Franc A, de Ruiter PC, Pascual M (2011) Robust scaling in ecosystems and the meltdown of patch size distributions before extinction: Patch size distributions towards extinction. Ecology Letters 14(1):29-35, DOI 10.1111/j.1461-0248.2010.01553.x, URL http://doi.wiley.com/10.1111/ j.1461-0248.2010.01553.x

Kéfi S, Holmgren M, Scheffer M (2016) When can positive interactions cause alternative stable states in ecosystems? Functional Ecology 30(1):88-97, DOI 10.

1111/1365-2435.12601, URL http://doi.wiley.com/10.1111/1365-2435. 12601

Le Galliard JF, Ferrière R, Dieckmann U (2003) The adaptive dynamics of altruism in spatially heterogeneous populations. Evolution 57(1):1-17, DOI 10.1111/j. 0014-3820.2003.tb00211.x, URL https://onlinelibrary.wiley.com/doi/ $\mathrm{abs} / 10.1111 / \mathrm{j} .0014-3820.2003 . t b 00211$. $\mathrm{x}$

Levine JM, Bascompte J, Adler PB, Allesina S (2017) Beyond pairwise mechanisms of species coexistence in complex communities. Nature 546(7656):56-64, DOI

10.1038/nature22898, URL http://www.nature.com/doifinder/10.1038/ nature22898

Lind EM, Borer E, Seabloom E, Adler P, Bakker JD, Blumenthal DM, Crawley M, Davies K, Firn J, Gruner DS, Stanley Harpole W, Hautier Y, Hillebrand H, Knops J, Melbourne B, Mortensen B, Risch AC, Schuetz M, Stevens C, Wragg PD (2013) Life-history constraints in grassland plant species: a growth-defence trade-off is the norm. Ecology Letters 16(4):513-521, DOI 10.1111/ele.12078, URL http: //onlinelibrary.wiley.com/doi/10.1111/ele.12078/abstract

Lortie CJ, Callaway RM (2006) Re-analysis of meta-analysis: support for the stressgradient hypothesis. Journal of Ecology 94(1):7-16, DOI 10.1111/j.1365-2745. 2005.01066.x, URL http://doi.wiley.com/10.1111/j.1365-2745.2005. $01066 . \mathrm{x}$

Lortie CJ, Filazzola A, Sotomayor DA (2016) Functional assessment of animal interactions with shrub-facilitation complexes: a formal synthesis and conceptual framework. Functional Ecology 30(1):41-51, DOI 10.1111/1365-2435.12530, URL http://doi.wiley.com/10.1111/1365-2435.12530

Muko S, Iwasa Y (2000) Species Coexistence by Permanent Spatial Heterogeneity in a Lottery Model. Theoretical Population Biology 57(3):273-284, DOI 10.1006/ 
tpbi.2000.1456, URL http://www.sciencedirect.com/science/article/ pii/S0040580900914564

Olff H, Vera FWM, Bokdam J, Bakker ES, Gleichman JM, Maeyer Kd, Smit R (1999) Shifting mosaics in grazed woodlands driven by the alternation of plant facilitation and competition. Plant Biology 1(2):127-137, URL http://onlinelibrary . wiley.com/doi/10.1111/j.1438-8677.1999.tb00236.x/abstract

Pacala SW, Crawley MJ (1992) Herbivores and Plant Diversity. The American Naturalist 140(2):243-260, DOI 10.1086/285411, URL https://www . journals.uchicago.edu/doi/abs/10.1086/285411, publisher: The University of Chicago Press

Peco B, de Pablos I, Traba J, Levassor C (2005) The effect of grazing abandonment on species composition and functional traits: the case of dehesa grasslands. Basic and Applied Ecology 6(2):175-183, DOI 10.1016/j.baae.2005.01.002, URL http:// linkinghub.elsevier.com/retrieve/pii/S1439179105000034

Petzoldt T, Rinke K (2007) simecol: An Object-Oriented Framework for Ecological Modeling in R. Journal of Statistical Software 22(9):1-31, DOI 10.18637/jss.v022. i09, URL http: //www . jstatsoft. org/v22/i09

R Core Team (2017) R: A Language and Environment for Statistical Computing. R Foundation for Statistical Computing, Vienna, Austria, URL https://www . R-project.org/

Rietkerk M, van de Koppel J (2008) Regular pattern formation in real ecosystems. Trends in Ecology \& Evolution 23(3):169-175, DOI 10.1016/j. tree.2007.10.013, URL http://linkinghub.elsevier.com/retrieve/pii/ S0169534708000281

Rietkerk M, Ketner P, Burger J, Hoorens B, Olff H (2000) Multiscale soil and vegetation patchiness along a gradient of herbivore impact in a semi-arid grazing system in West Africa. Plant Ecology 148(2):207-224, URL http://link.springer. com/article/10.1023/A:1009828432690

Rietkerk M, Boerlijst MC, Langevelde Fv, HilleRisLambers R, Koppel Jvd, Kumar L, Prins HHT, Roos aAMd (2002) Self-Organization of Vegetation in Arid Ecosystems. The American Naturalist 160(4):524-530, URL http://www . jstor .org/ stable/10.1086/342078

Rietkerk M, Dekker SC, Ruiter PCd, Koppel Jvd (2004) Self-Organized Patchiness and Catastrophic Shifts in Ecosystems. Science 305(5692):1926-1929, DOI

10.1126/science.1101867, URL http://www . sciencemag.org/content/305/ 5692/1926

Scheffer M, Carpenter S, Foley J, Folke C, Walker B (2001) Catastrophic shifts in ecosystems. NATURE 413(6856):591-596, DOI 10.1038/35098000

Schneider FD, Kéfi S (2016) Spatially heterogeneous pressure raises risk of catastrophic shifts. Theoretical Ecology 9(2):207-217, DOI 10.1007/s12080-015-0289-1, URL http://link.springer.com/10.1007/ s12080-015-0289-1

Schöb C, Butterfield BJ, Pugnaire FI (2012) Foundation species influence trait-based community assembly. New Phytologist 196(3):824-834, DOI 10. 1111/j.1469-8137.2012.04306.x, URL http://doi.wiley.com/10.1111/j . $1469-8137.2012 .04306 . \mathrm{x}$ 
Schöb C, Callaway RM, Anthelme F, Brooker RW, Cavieres LA, Kikvidze Z, Lortie CJ, Michalet R, Pugnaire FI, Xiao S, Cranston BH, García MC, Hupp NR, Llambí LD, Lingua E, Reid AM, Zhao L, Butterfield BJ (2014) The context dependence of beneficiary feedback effects on benefactors in plant facilitation. New Phytologist 204(2):386-396, DOI 10.1111/nph.12908, URL http://doi .wiley.com/ 10.1111/nph.12908

Schöb C, Macek P, Pistón N, Kikvidze Z, Pugnaire FI (2017) A trait-based approach to understand the consequences of specific plant interactions for community structure. Journal of Vegetation Science 28(4):696-704, DOI 10.1111/jvs.12523, URL http://onlinelibrary.wiley.com/doi/10.1111/jvs.12523/abstract

Smit C, Den Ouden J, MüLler-SchäRer H (2006) Unpalatable plants facilitate tree sapling survival in wooded pastures: Unpalatable plants facilitate tree saplings survival. Journal of Applied Ecology 43(2):305-312, DOI 10.1111/j.1365-2664. 2006.01147.x, URL http://doi.wiley.com/10.1111/j.1365-2664.2006. $01147 . \mathrm{x}$

Smit C, Vandenberghe C, den Ouden J, Müller-Schärer H (2007) Nurse plants, tree saplings and grazing pressure: changes in facilitation along a biotic environmental gradient. Oecologia 152(2):265-273, DOI 10.1007/s00442-006-0650-6, URL http://link.springer.com/10.1007/s00442-006-0650-6

Soetaert K, Petzoldt T, Setzer RW (2010) Solving Differential Equations in R: Package deSolve. Journal of Statistical Software 33(9):1-25, DOI 10.18637/jss.v033. i09, URL http://www.jstatsoft. org/v33/i09

Soliveres S, Eldridge DJ, Hemmings F, Maestre FT (2012) Nurse plant effects on plant species richness in drylands: The role of grazing, rainfall and species specificity. Perspectives in Plant Ecology, Evolution and Systematics 14(6):402-410, DOI 10.1016/j.ppees.2012.09.003, URL http://linkinghub.elsevier.com/ retrieve/pii/S1433831912000558

Stachowicz JJ (2001) Mutualism, Facilitation, and the Structure of Ecological Communities Positive interactions play a critical, but underappreciated, role in ecological communities by reducing physical or biotic stresses in existing habitats and by creating new habitats on which many species depend. Bioscience 51(3):235246, URL http://bioscience.oxfordjournals .org/content/51/3/235. short

Valiente-Banuet A, Verdú M (2007) Facilitation can increase the phylogenetic diversity of plant communities. Ecology Letters 10(11):1029-1036, DOI 10. 1111/j.1461-0248.2007.01100.x, URL http://doi.wiley.com/10.1111/j. $1461-0248.2007 .01100 \cdot x$

Viola DV, Mordecai EA, Jaramillo AG, Sistla SA, Albertson LK, Gosnell JS, Cardinale BJ, Levine JM (2010) Competition-defense tradeoffs and the maintenance of plant diversity. Proceedings of the National Academy of Sciences 107(40):17217-17222, DOI 10.1073/pnas.1007745107, URL http://www . pnas.org/cgi/doi/10.1073/pnas.1007745107

Yoshida T, Hairston NG, Ellner SP (2004) Evolutionary trade-off between defence against grazing and competitive ability in a simple unicellular alga, Chlorella vulgaris. Proceedings of the Royal Society B: Biological Sciences 271(1551):1947-1953, DOI 10.1098/rspb.2004.2818, URL http://rspb. 
royalsocietypublishing.org/cgi/doi/10.1098/rspb.2004.2818 
A
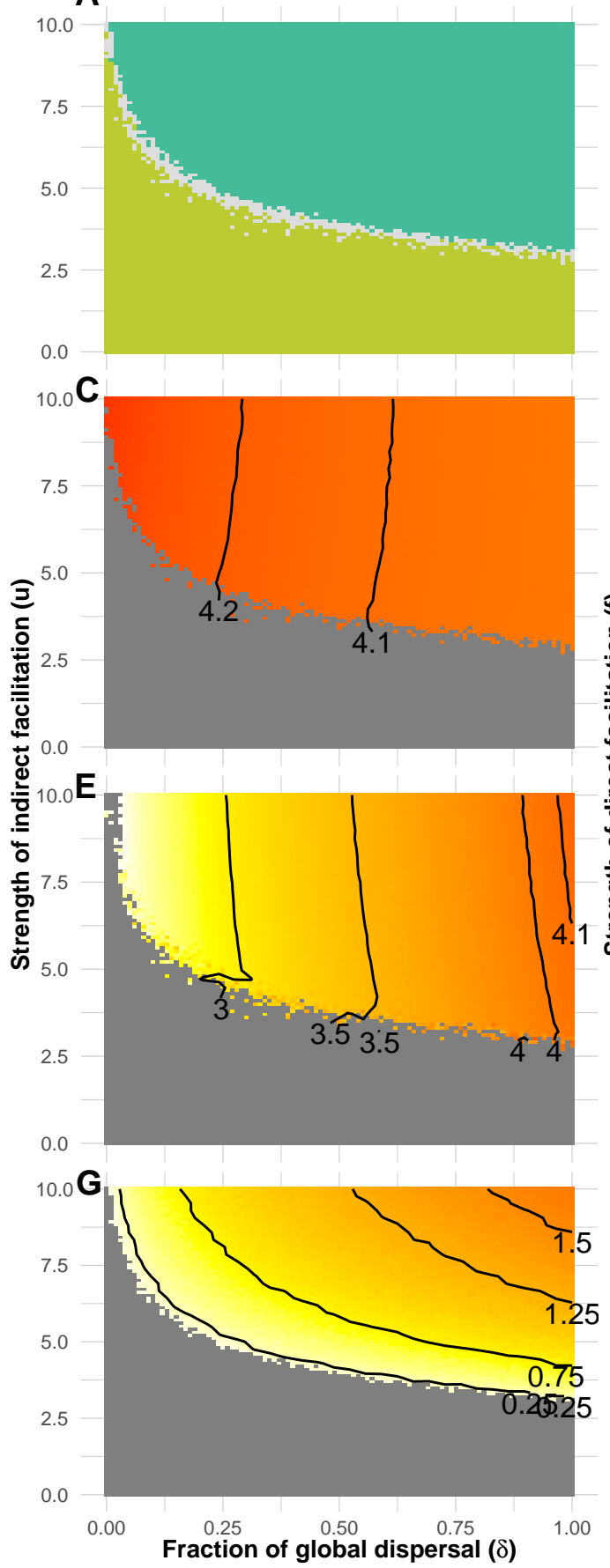

B
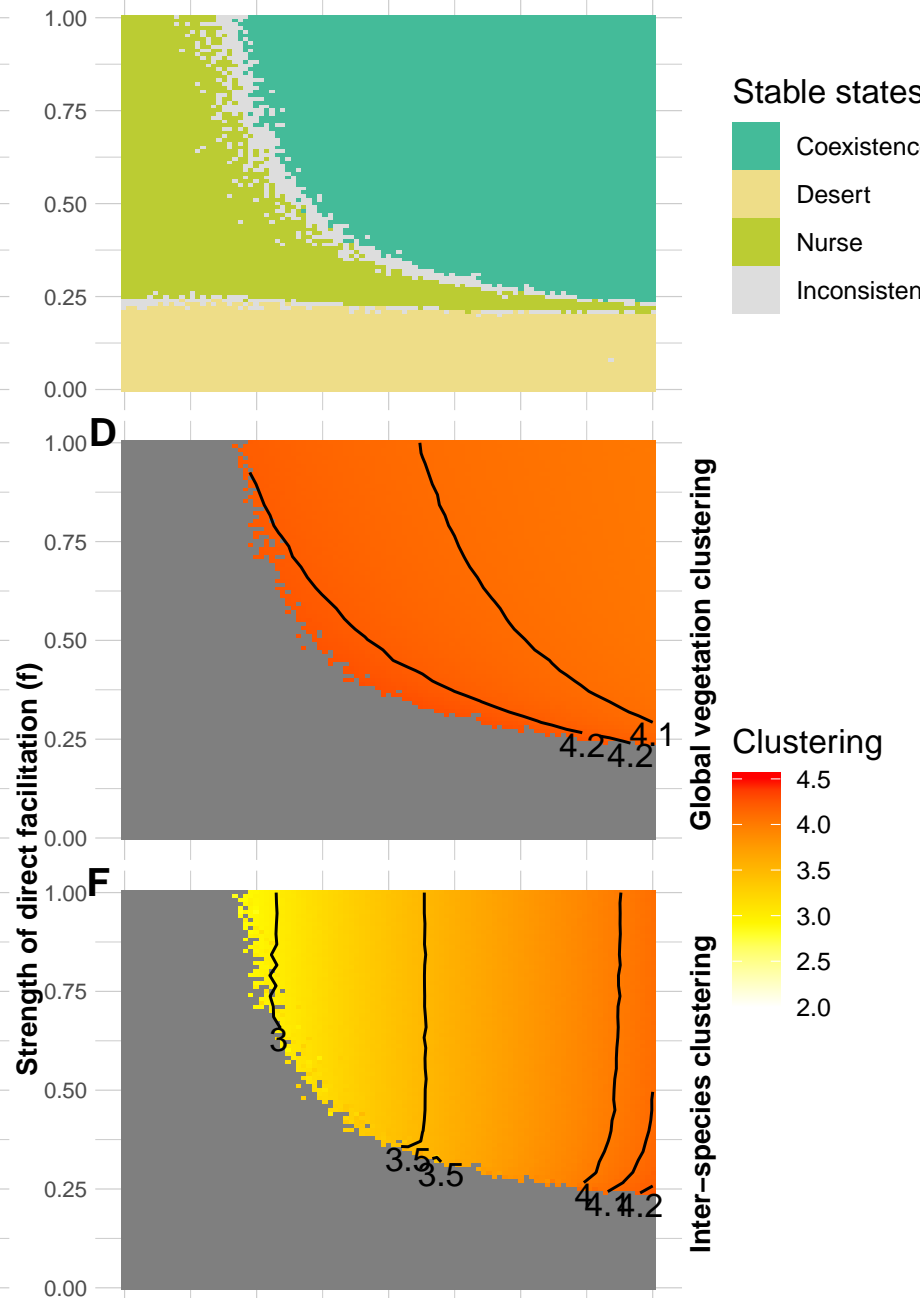

Stable states

Coexistence

Desert

Nurse

Inconsistent

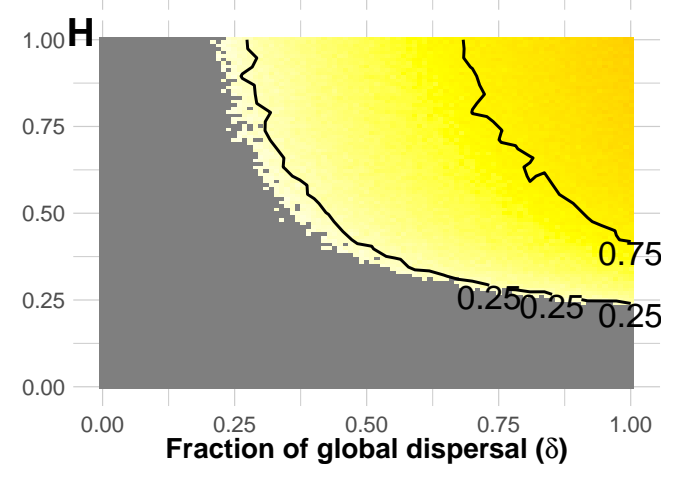

\section{Average \# of protegee neighbors for nurse cells}

Fig. 4 Vegetation clustering as a function of the fraction of global dispersal $(\delta)$ in abscissa, and the strength of indirect facilitation $(u)$ (left column, A, C, E, G) or the strength of direct facilitation $(f)$ (right column, B, D, F, H). A and B: stable states considering high starting vegetation cover (cf Figure 2). C and $\mathrm{D}$ : clustering of the vegetation without species distinction. $\mathrm{E}$ and $\mathrm{F}$ : clustering between the nurse and the protegee species. $\mathrm{G}$ and $\mathrm{H}$ : the average number of protegee cells in the direct neighbourhood of nurse cells. Simulation results from the cellular automaton. The resolution of the parameter gradient is .1, .01 and .01 for respectively $u, f$ and $\delta$. 